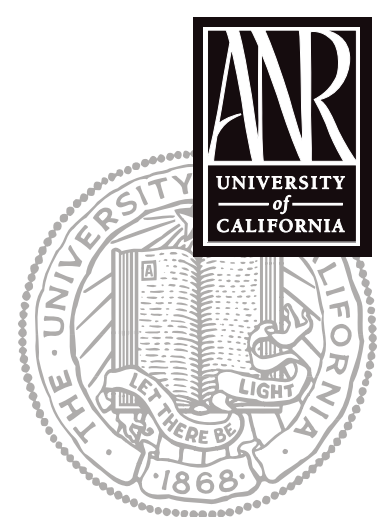

UNIVERSITY OF CALIFORNIA

Division of Agriculture and Natural Resources http://anrcatalog.ucdavis.edu

\title{
Genetic Engineering and Testing Methodologies
}

ALAN McHUGHEN, Cooperative Extension Plant Biotechnologist, Department of Botany and Plant Sciences, University of California, Riverside

Genetic engineering (GE) in crops is becoming more and more widespread; in 2005 an estimated 222 million acres ( 90 million ha) of GE crops were grown by 8.5 million farmers in 21 countries worldwide (James 2006). In spite of the rapid adoption of these "transgenic" crops by farmers, some people remain skeptical and even fearful of these plants, demanding strict controls on their cultivation, distribution, and consumption. Therefore, many GE crops and the foods and feeds derived from them should be monitored to ensure that adventitious (unintended) presence (AP) is kept below agreed limits or tolerances. Ensuring reasonable segregation allows the coexistence of different crops, whether genetically engineered, organic, or conventional. Monitoring requires accurate detection methods, especially in jurisdictions where thresholds are either not set at all ("zero tolerance") or where only minute quantities of AP are allowed. These issues are particularly crucial on the farm, where seed commingling and AP of various contaminants is inevitable and occurs as a matter of course.

\section{What is a genetically engineered plant?}

GE plants are genetically modified using recombinant DNA (rDNA) methods of breeding. Such plants may be altered to provide better protection against insect pests or diseases, or to withstand herbicides to enable better weed control. The actual trait endowed on the plant can differ, but the one feature all GE plants have in common is the addition of new genetic material, DNA, to complement the DNA already present in the plant.

\section{What is DNA and in what ways does genetic engineering alter the plant?}

DNA is a long molecule composed of linked arrangements of the four DNA bases, abbreviated A, T, C, and G. These four bases of DNA are arranged much like the 26 letters of the English language make up words. That is, just as different English words are spelled using specific sequences of the 26 letters, different specific sequences of the four DNA bases spell out different genes on the DNA. These different genes provide a recipe to make a particular protein. The presence or absence of a particular protein provides each trait, such as herbicide tolerance or disease resistance.

The base sequence of the additional DNA differs to some degree from the native DNA already present in the plant, and so the inserted DNA base sequence difference can form the basis for distinguishing the GE plant from the non-GE "parent" plant. In Bt corn, for example, the Bt insecticidal gene (DNA) from bacteria is transferred and inserted into the corn DNA. Because corn DNA does not normally carry this particular (Bt) sequence of DNA bases, searching for and finding this specific piece of DNA among regular corn DNA can identify Bt corn among regular, non-Bt corn.

Also, the inserted DNA usually results in a protein new to that plant or one exploited to distinguish the GE plant from its non-GE parent plant. Taking the $\mathrm{Bt}$ corn example again, the Bt DNA in the corn serves as a recipe to make Bt protein, the 
substance with insecticidal properties (sensitive insects die upon eating the Bt protein). Because corn ordinarily doesn't produce Bt protein, the presence of the Bt protein in a sample of corn can serve to identify the respective corn as GE.

Finally, the actions of the new proteins, especially if they are enzymes, can produce new metabolites in the GE plant that can be detected and may serve as the basis for distinguishing GE plants from non-GE plants of the same species.

Genetic engineering can also result in the inhibition or removal of endogenous proteins or metabolites, and the absence of these proteins or metabolites also can provide a means to distinguish GE from non-GE plants.

\section{How can genetically engineered food be identified?}

GE foods and feeds are those produced from GE plants, animals, or microbes. Unfortunately, and unlike GE plants, GE foods do not necessarily share any tangible, measurable features. Indeed, there is no standard definition of a GE food, and different countries have different and sometimes contradictory definitions. For example, in Europe, vegetable oil made from GE corn (grown mainly in the United States) is considered a GE food, even if there is no DNA or protein present in the consumed food. In contrast, cheese and other foods made from GE proteins (from GE microbes grown mainly in Europe) are not considered GE foods, even though GE proteins can be readily detected in the consumed food.

In other jurisdictions, GE foods are defined as having detectable GE components-from changes in either specific DNA, proteins, or metabolites. Foods lacking such distinguishing features are not considered GE foods, even if they were derived from GE plants. Vegetable oil made from GE corn is one example, where the oil itself, the food, is identical in every measurable way to oil from non-GE corn.

\section{How can genetically engineered plants be identified?}

Genetically engineered plants by definition have some genetic (DNA) sequences different from those of regular, non-GE plants. This means that testing the DNA for those distinctions becomes the definitive means to detect a given GE plant. In addition to gene changes, there may also be changes to the proteins in a GE plant. As mentioned above, a Bt corn plant will carry the Bt protein (as well as the Bt DNA sequence). However, some kinds of GE plants may be missing a particular protein ordinarily present, or the amount of proteins present may be changed. Finally, depending on the specific GE variety, other substances may be present or absent, and so detecting those metabolites might provide the key to detecting GE plants.

All plants (and plant parts, cells, seeds, etc.) naturally contain DNA, so testing plants or their parts for the mere presence of DNA cannot ascertain GE plants. Instead, detecting a specific GE DNA base sequence requires some knowledge of the inserted, engineered DNA. Also, each cell in the plant contains the same total DNA sequence, and it is difficult to detect the one or two inserted DNA sequences from the thousands of regular genes already present. That is, GE might add one or two genes to a plant cell already home to 30,000 genes. This presents a problem similar to looking for a needle, not in a haystack but in a needlestack. Fortunately, several different kinds of tests or assays seek out the unique GE DNA sequences. Each method has strengths and weaknesses, so choosing a method for detecting GE plants requires balancing these features.

Another complication is that each approved GE plant variety may have different inserted sequences. For example, the DNA sequence of the Bt gene is different from that of the Roundup Ready (RR) gene, so testing a GE RR plant for the Bt gene will indicate that the plant is non-GE because it carries the RR gene, not the Bt gene. This doesn't mean all 60 or so approved GE crop varieties are unique, since many do carry some sequences in common. In particular, many commercialized GE plants house 
the CaMV DNA sequence (used to help activate or "express" the new gene), so the sequence of this piece of DNA is often used to detect GE plants, as it will detect many different GE varieties. But if little is known about the inserted DNA, particularly as more kinds of modification are made, it becomes very difficult to make a definitive decision about the GE status. So, given these considerations, what are some of the technical methods used to detect GE plants?

\section{What is PCR (polymerase chain reaction) and can it be used to test for GE DNA?}

PCR involves making copies of specific sequences of DNA, much like a photocopier makes copies of a page of words. In the PCR, though, the reaction is chemical in that small pieces of known sequence from the inserted DNA are added to a pool of DNA extracted from the plant in question. If the plant is a non-GE plant, it will lack the inserted DNA and no reaction will occur and consequently no copies will be made. If the plant is GE and the inserted DNA sequence is present, the small pieces will attach to the inserted DNA, and then an enzyme (DNA polymerase) will fill in the gap of the entire DNA sequence between where the two pieces have attached. This makes a new copy of the inserted DNA with the identical DNA base sequence. The "chain reaction" means the whole process starts over again, such that now each copy of the inserted DNA is used as a template, resulting in four copies, which cycles again to make 8 copies, then 16, then 32, then 64 and so on. Each cycle takes only a few minutes, and a test typically runs overnight for 25 to 30 cycles. In the morning, the test tube has many copies of the insert DNA, which because of the large quantity is easily detected and the plant being tested is scored as GE.

\section{Are there other methods that can be used to test for GE DNA or RNA?}

Whereas PCR makes detection simple by increasing the amount of inserted DNA sequence present, Southern blots (named after the scientist who developed the technique) work by making the inserted (GE) DNA stand out. In a Southern blot, the unique DNA sequences are again used to initially detect the presence of the inserted DNA, but in this method a synthetic piece of DNA is labeled with either radioactivity or fluorescence and allowed to attach to the GE sequence. If the DNA does not carry the inserted sequence, the labeled synthetic DNA has nothing to attach to and the result is negative, or non-GE. If the GE DNA is present in the sample, the radioactive sequence binds to the inserted DNA and is readily detected due to the radioactivity or fluorescence.

A limitation of both PCR and Southern assays is that they can tell the presence of specific DNA sequences, but they cannot tell whether the inserted gene is actually working, or "expressed." The Northern blot is similar to the Southern, but it is able to detect inserted genes that are being actively expressed. It does this by seeking and detecting RNA, a chemical relative of DNA used as an essential intermediary in the construction of specific proteins from the DNA recipe.

\section{Are there methods that can be used to test for the presence of GE proteins?}

Like DNA, all plants and plant parts naturally carry thousands of different proteins, so a test based on the mere presence of protein does not help to distinguish GE plants. Instead, some knowledge of the novel (GE) protein (or absence of native protein) is required beforehand. Like tests based on DNA sequence, several protein-based tests can distinguish GE from non-GE plants.

Western blot is a variation of the Southern, but it seeks and detects the presence of the new protein expressed by the GE inserted gene. It does this by using artificial antibodies that bind specifically to the GE protein, and the combination of the antibody with the protein can be visualized and scored. The process involves sampling the plant and extracting the bulk of proteins. The antibody is applied to the sample 
of proteins, and if the specific GE-derived protein is not present, the antibody will not bind and no visualization occurs; the plant sampled is scored as non-GE. If the protein is present, the antibody sticks to it and the visual test shows the plant to be GE.

Other tests are also based on the same immunological theme of visualizing the GE derived proteins: ELISA, dipstick, and others all rely on the binding of specific antibodies to the GE-derived protein. In each case, the antibodies are highly specific to the new protein, and scoring is based on the successful attachment of the antibody with the new protein.

\section{What are the limitations of these different testing methodologies?}

All of these diagnostic detection tests have strengths and weaknesses. No one test, taken in isolation, should be considered definitive. Instead, a definitive decision should be based on several test results, preferably those combining both a nucleic acid (DNA and/ or RNA) with a protein detection assay. PCR is a very powerful and sensitive test, being able to detect down to the $0.01 \%$ level of presence, but it can also yield false results (both positive and negative) due to cross-contamination or inadvertent admixtures, DNA decay, poor technique, and so on.

The protein-based tests are also subject to limitations and can yield incorrect results, both positive and negative. The test could fail to detect a true GE plant if, for example, the seeds did not carry the GE derived protein, but the rest of the plant did. A false positive result could occur if the protein was present in a non-GE plant: for example, if Bt pesticide were sprayed on a non-GE corn field, the immunological tests might incorrectly score positive from combining with the sprayed Bt.

Sampling is also an important issue in detection reliability. As demands for lower and lower limits of detection are mandated, a practical result is an increase in sampling size and frequency. For example, in order to reliably test at the 5\% level, a standard in agriculture for all manner of adventitious presence, only one seed in twenty need score positive, and only a small sample of seeds from the lot need be taken to achieve this with a reasonable degree of confidence. But as adventitious GE seeds are often limited to $1 \mathrm{GE}$ seed in 10,000 seeds, a much bigger sample of seeds must be taken to achieve the same degree of confidence. It is much easier to detect 1 wayward seed in 20 than 1 in 10,000, so more frequent samples, and larger sample sizes, are required to detect the GE seeds.

Sensitivity is also crucial and must be placed in context. If a test can detect one GE corn kernel in a bagful, the assay is clearly very sensitive. But is it meaningful, considering the other contaminants, weed seeds, dirt, insect parts, etc., in that same bag of grain? Such level of presence may be important for contractual market obligations, but it is unlikely to be meaningful for federally regulated health or ecological concerns, as enforced by the USDA. That level of sensitivity is also much greater than the adventitious tolerance levels that are generally required for seed purity, as established by the Association of Seed Certifying Agencies (AOSCA), which usually sets adventitious presence tolerance levels in the parts per hundred ( 1 to $2 \%$ ), not in parts per thousand (0.1\%) or million $(0.0001 \%)$.

Farmers have always had the choice of what crops to grow and have always had to contend with commingling, admixtures, and other contaminants in their crops. As a result, farmers have a history of stewardship and neighborly cooperation to restrict the flow of their own crops and weeds into neighboring farms and to allow reasonable amount of adventitious presence in their own. With GE crops, farmers have more cropping choices but also more responsibilities. The development of modern methods to monitor and detect different crop varieties, especially GE crop varieties, can help to facilitate the continued coexistence of GE, conventional, and organic crop production systems. 


\section{PERSPECTIVE}

Wherever farmers have been allowed to grow GE crops, they have rapidly adopted the new GE varieties. But good stewardship of GE crops, just as with conventional crop varieties, requires good management to minimize the spread of GE traits into crops or foods where they are unwanted. Fortunately, several accurate and sensitive tests are available to detect and measure adventitious presence of GE crops and foods. Good stewardship and sensible application of such tests provides all farmers the ability to grow a diversity of crops and foods and live in coexistence with neighboring farmers with different farming practices.

\section{REFERENCE}

James, C. 2006. ISAAA Briefs No. 34-2005, Global status of commercialized biotech/ gm crops: 2005. ISAAA Web site, http://www.isaaa.org.

To order or obtain printed ANR publications and other products, visit the ANR Communication Services online catalog at http://anrcatalog.ucdavis.edu. You can also place orders by mail, phone, or FAX, or request a printed catalog of our products from:

University of California

Agriculture and Natural Resources

Communication Services

6701 San Pablo Avenue, 2nd Floor

Oakland, California 94608-1239

Telephone: (800) 994-8849 or (510) 642-2431

FAX: (510) 643-5470

E-mail inquiries: danrcs@ucdavis.edu

An electronic version of this publication is available on the ANR Communication Services Web site at http://anrcatalog.ucdavis.edu.

Publication 8190

(C) 2006 by the Regents of the University of California, Division of Agriculture and Natural Resources. All rights reserved.

The University of California prohibits discrimination or harassment of any person on the basis of race, color, national origin, religion, sex, gender identity, pregnancy (including childbirth, and medical conditions related to pregnancy or childbirth), physical or mental disability, medical condition (cancer-related or genetic characteristics), ancestry, marital status, age, sexual orientation, citizenship, or status as a covered veteran (covered veterans are special disabled veterans, recently separated veterans, Vietnam era veterans, or any other veterans who served on active duty during a war or in a campaign or expedition for which a campaign badge has been authorized) in any of its programs or activities. University policy is intended to be consistent with the provisions of applicable State and Federal laws.

Inquiries regarding the University's nondiscrimination policies may be directed to the Affirmative Action/Staff Personnel Services Director, University of California, Agriculture and Natural Resources, 300 Lakeside Drive, 6th Floor, Oakland, CA 94612-3550 (510) 987-0096. For a free catalog of other publications, call (800) 994-8849. For help downloading this publication, call (530) 754-5112.

To simplify information, trade names of products have been used. No endorsement of named or illustrated products is intended, nor is criticism implied of similar products that are not mentioned or illustrated.

This publication has been anonymously peer reviewed for technical accuracy by University of California scientists and other qualified professionals. This review process was managed by the ANR Associate Editor for Animal, Avian, Aquaculture, and Veterinary Sciences. 